Supplement of Atmos. Chem. Phys., 18, 5589-5605, 2018

https://doi.org/10.5194/acp-18-5589-2018-supplement

(C) Author(s) 2018. This work is distributed under

the Creative Commons Attribution 4.0 License.

(c) (1)

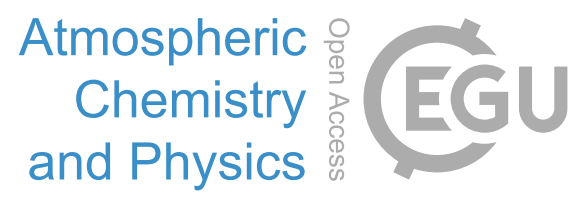

Supplement of

\title{
Analysis of European ozone trends in the period 1995-2014
}

\section{Yingying Yan et al.}

Correspondence to: Andrea Pozzer (andrea.pozzer@mpic.de)

The copyright of individual parts of the supplement might differ from the CC BY 4.0 License. 

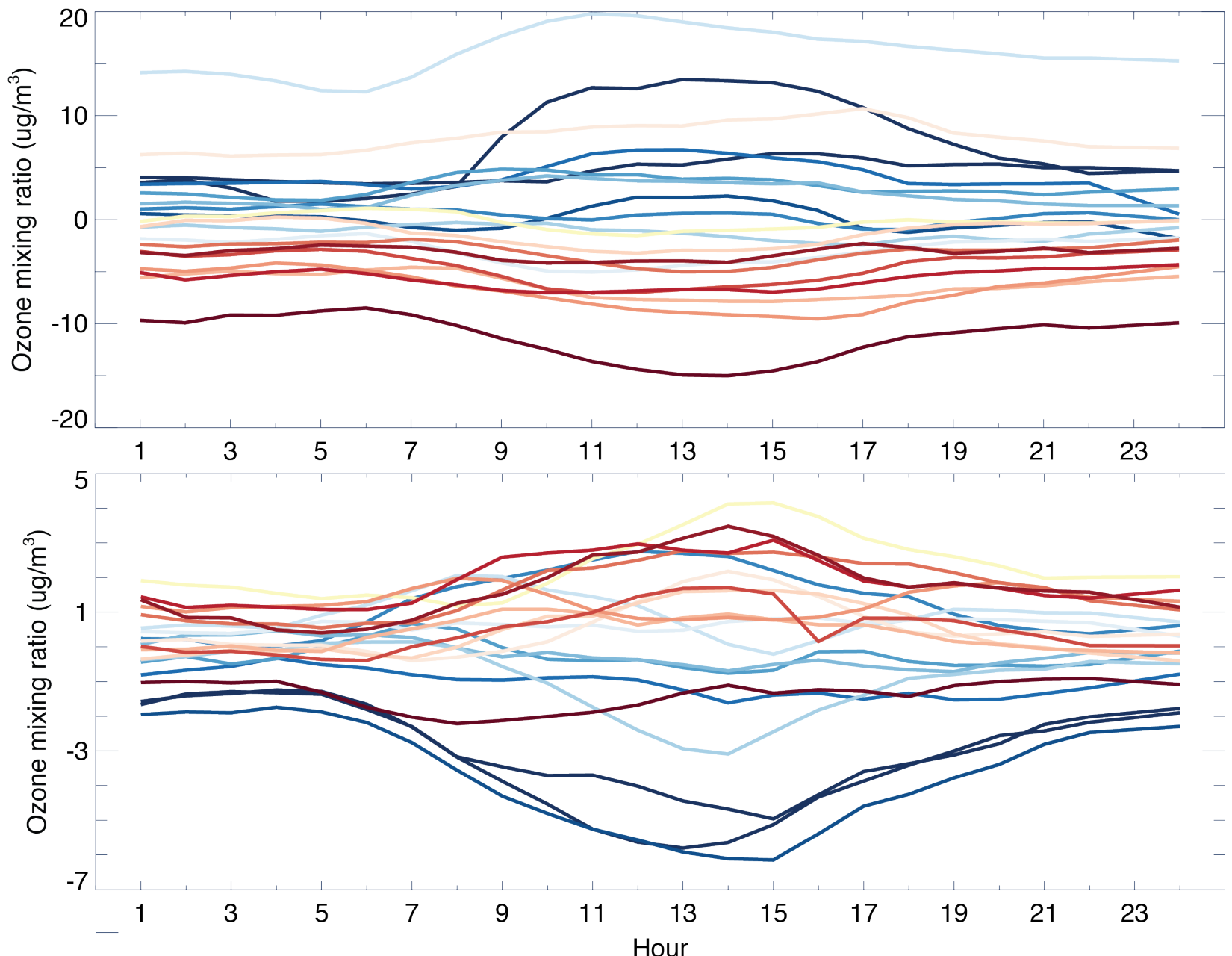

$\begin{array}{lllllll}1995 & 1998 & 2002 & 2006 & 2010 & 2014 & \text { Year }\end{array}$

Fig. S1. Evolution of the European annual ozone anomalies at each hour of the day for $95^{\text {th }}$ (top) and $5^{\text {th }}$ (bottom) percentiles. 


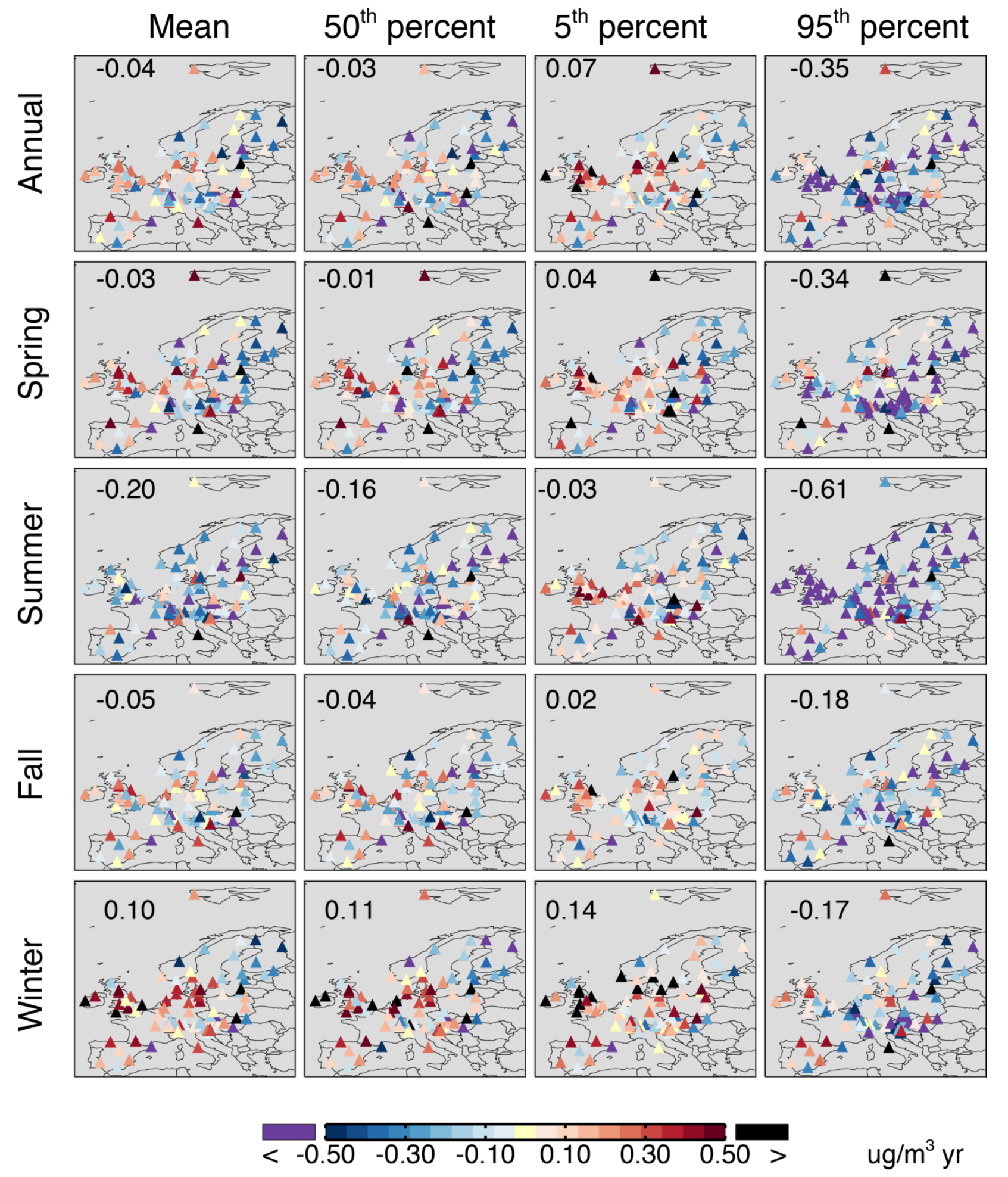

Fig. S2. Spatial distribution of measured nighttime ozone trends in $\mu \mathrm{g} / \mathrm{m}^{3} / \mathrm{yr}$ across the selected 93 sites for average, $5^{\text {th }}, 50^{\text {th }}$ and $95^{\text {th }}$ percentile ozone for the annual mean and four seasons. Also shown in each panel are the average trends over all sites. 

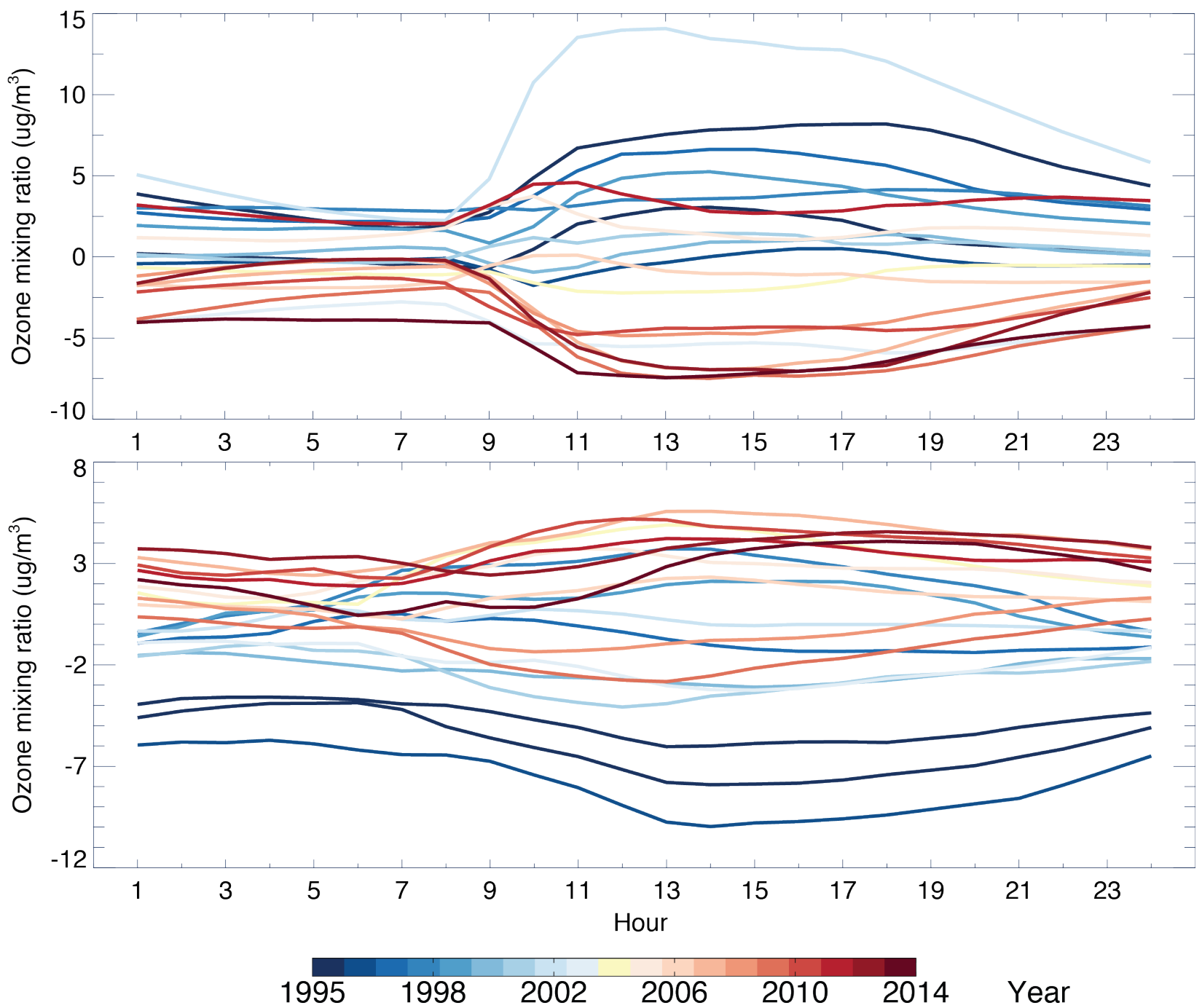

Fig. S3. Evolution of the modeled European annual ozone anomalies at each hour of the day for $95^{\text {th }}$ (top) and $5^{\text {th }}$ (bottom) percentiles. 


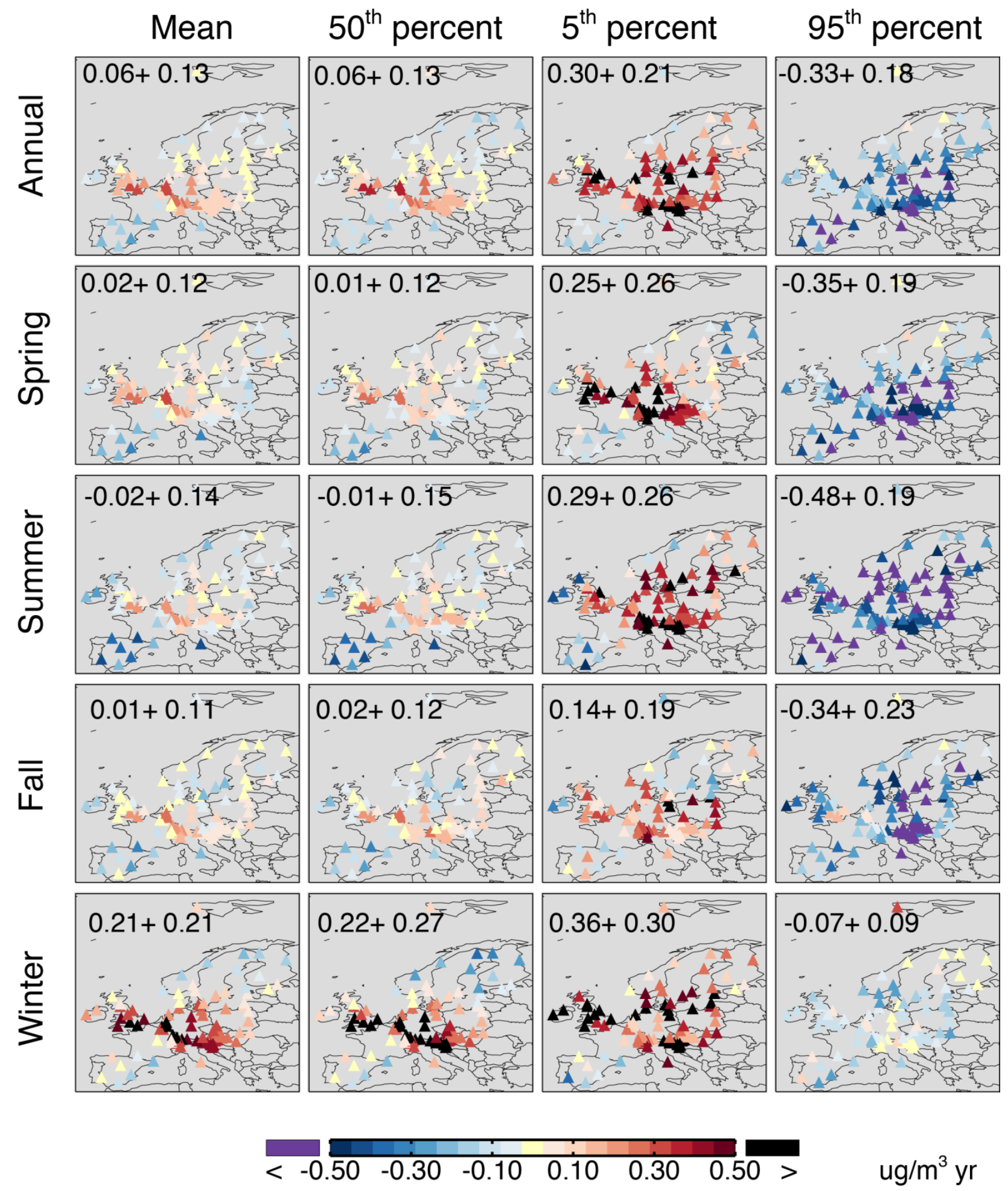

Fig. S4. Spatial distribution of simulated daily ozone trends by the EMAC model for average, $5^{\text {th }}, 50^{\text {th }}$ and $95^{\text {th }}$ percentile ozone for the annual mean and four seasons. Also shown in each panel are the average trends over all sites. 


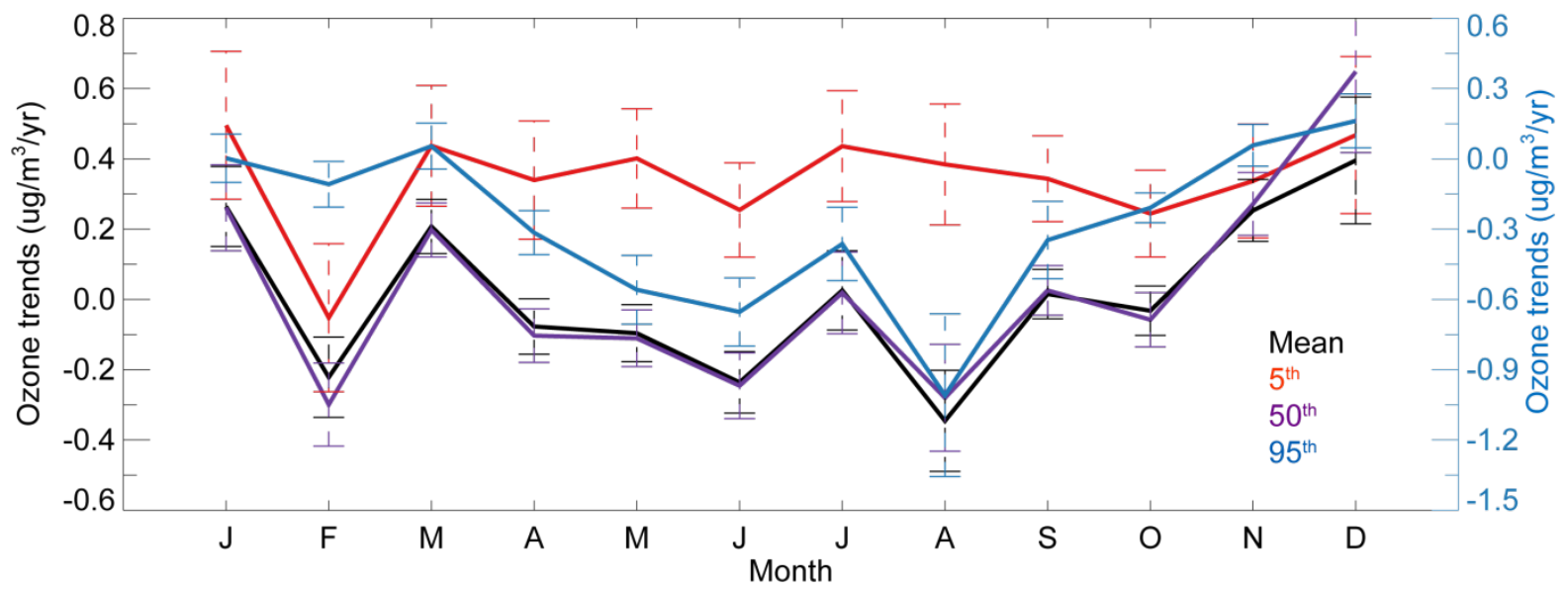

Fig. S5. Monthly trend in modeled surface ozone averaged over Europe. The black line shows the 1995-2014 linear trends in the European mean ozone for each month of the year, the red, purple and blue lines depict the observed trend for $5^{\text {th }}, 50^{\text {th }}$ and $95^{\text {th }}$ percentile ozone, respectively, and the dashed bars indicate their standard deviations. 


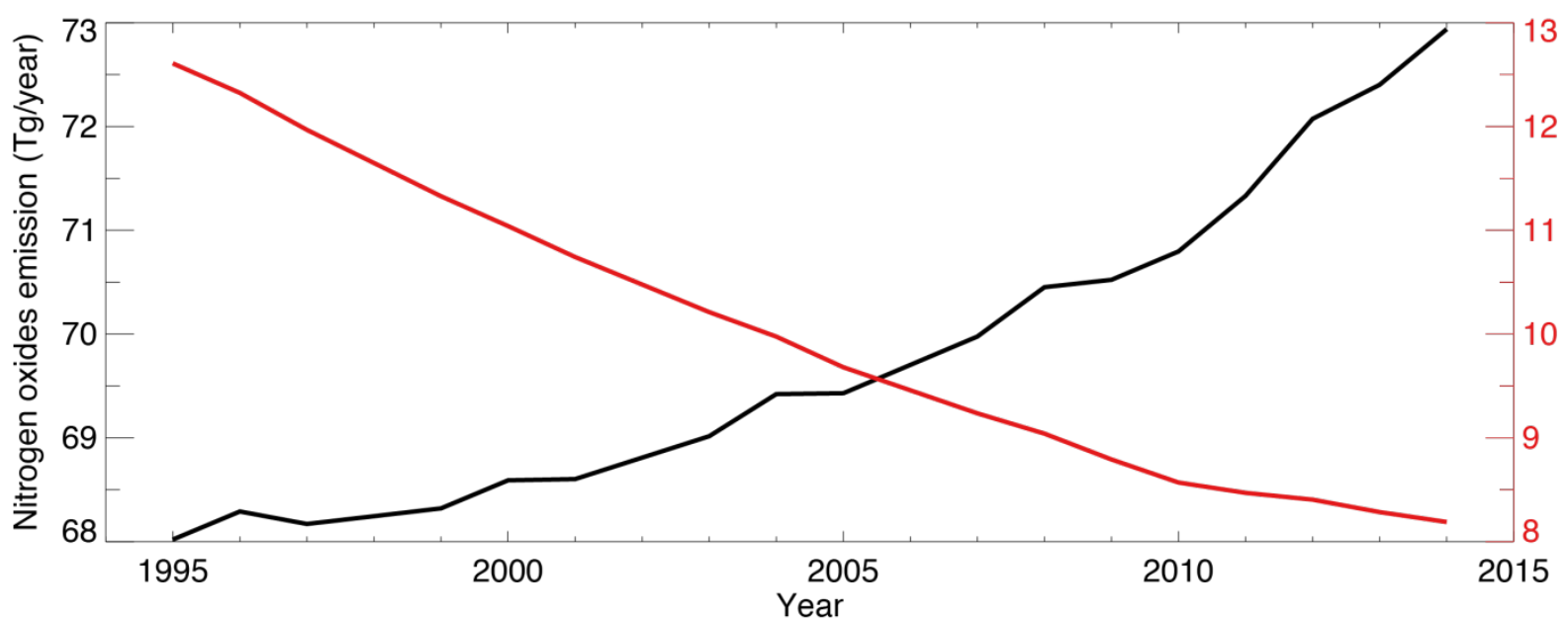

Fig. S6. Annual total nitrogen oxides emission over European (red) and global scale (black) based on the MACCity (MACC/CityZEN EU projects) emissions dataset. 

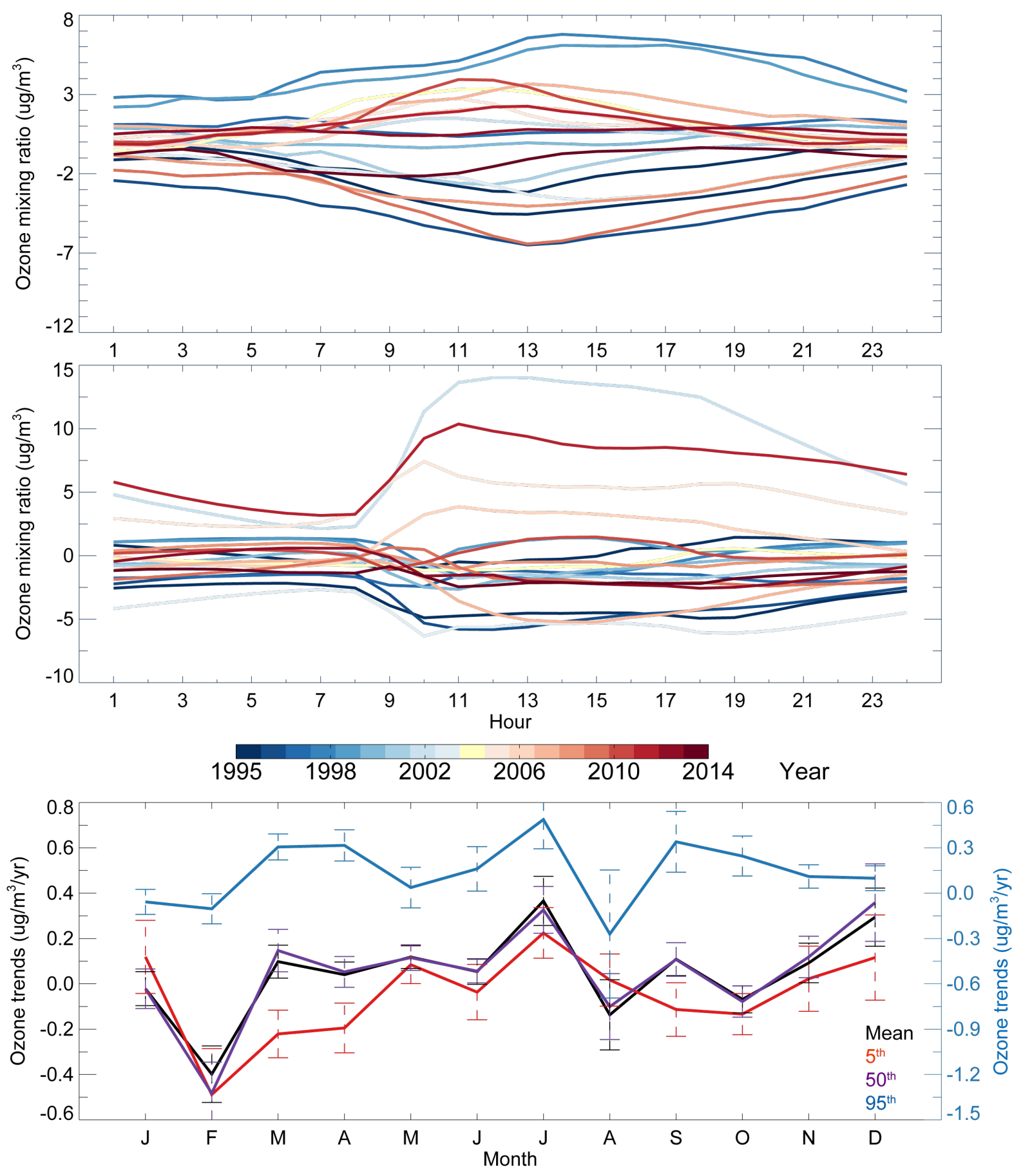

Fig. S7. Hourly evolutions for $5^{\text {th }}$ (top) and $95^{\text {th }}$ (middle) percentiles and monthly trend (bottom) in the modeled surface ozone by fixing anthropogenic emissions in the EMAC model. The black line shows the 1995-2014 linear trends in the European mean ozone for each hour of the day, the red, purple and blue lines depict the observed trends for $5^{\text {th }}, 50^{\text {th }}$ and $95^{\text {th }}$ percentile ozone, respectively, and the dashed bars indicate their standard deviations. 

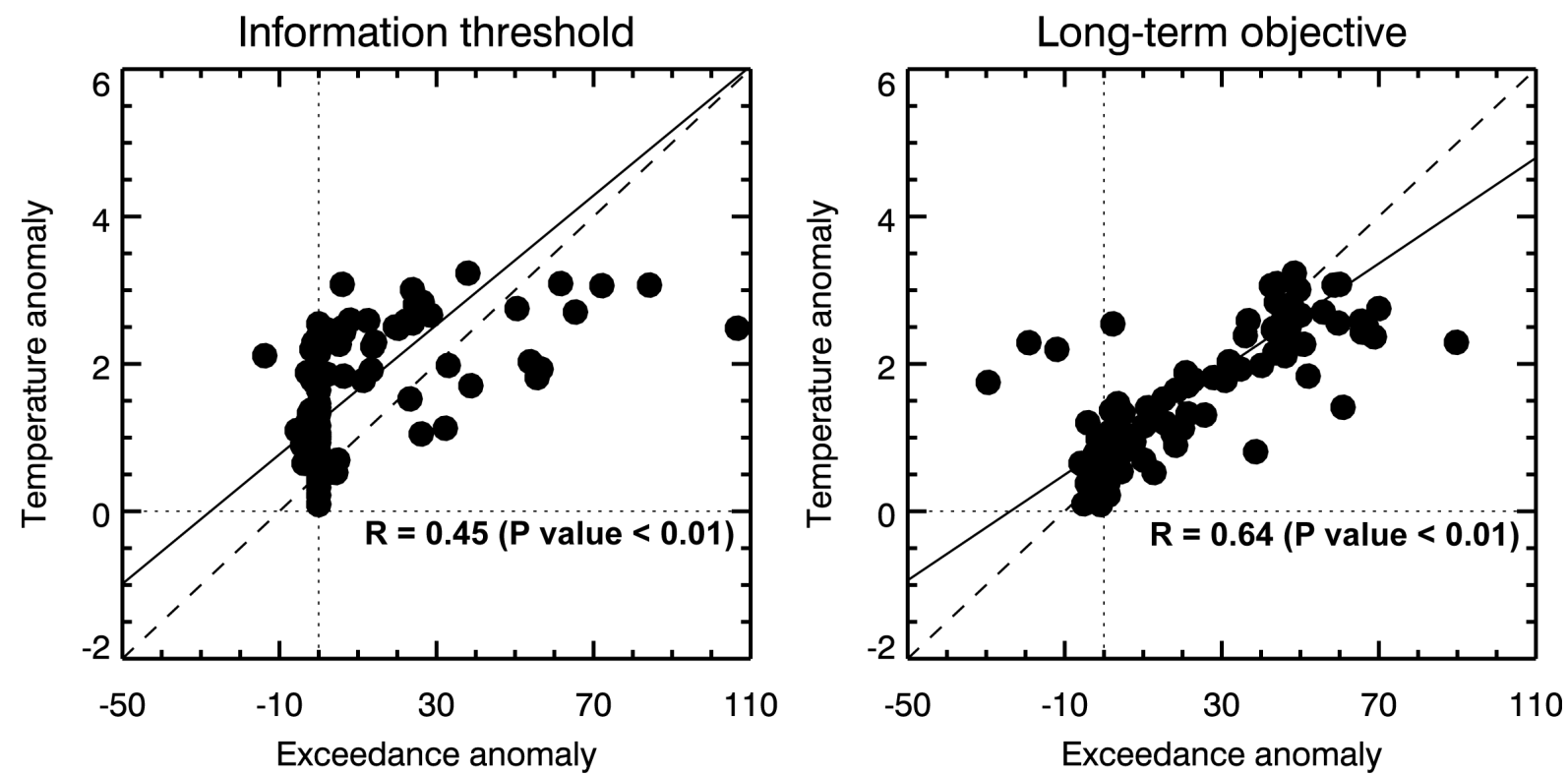

Fig. S8. Correlations between the 2-meter temperature anomalies in 2003, relevant to the averages over 1995-2002, and the exceedance anomalies for the information threshold as well as the long-term objective over the 93 sites. 

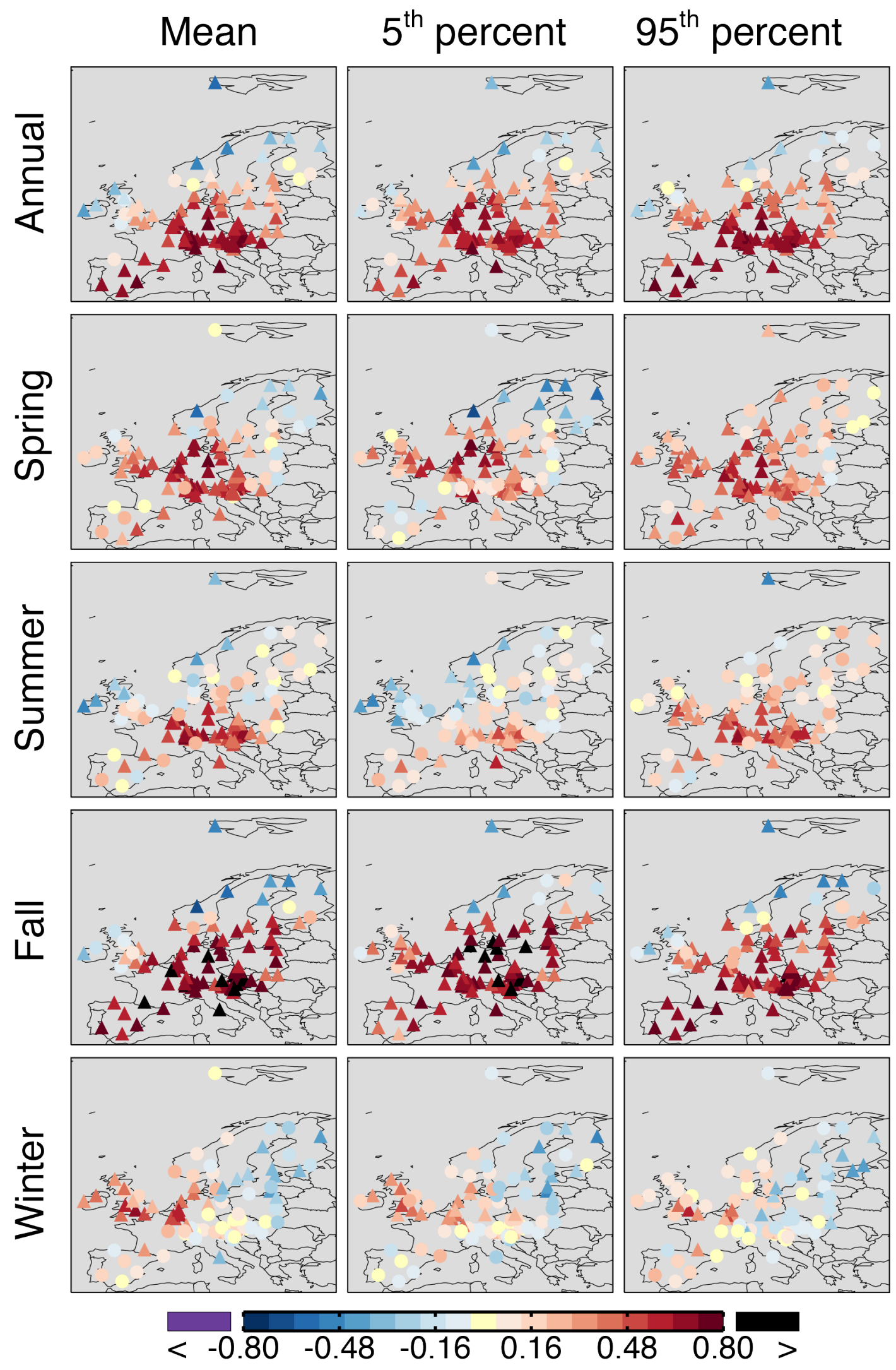

Fig. S9. Site-by-site correlations (triangle: P-value $<0.05$ under a T-test; circular: P-value $>$ 0.05 ) between the annual and seasonal monthly mean 2-meter temperature and monthly mean, $5^{\text {th }}$ and $95^{\text {th }}$ percentile ozone in the daily data, and during daytime as well as nighttime. 


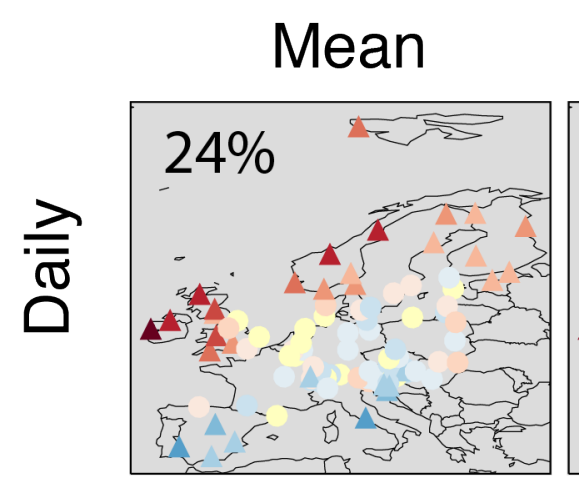

\section{$5^{\text {th }}$ percent $\quad 95^{\text {th }}$ percent}
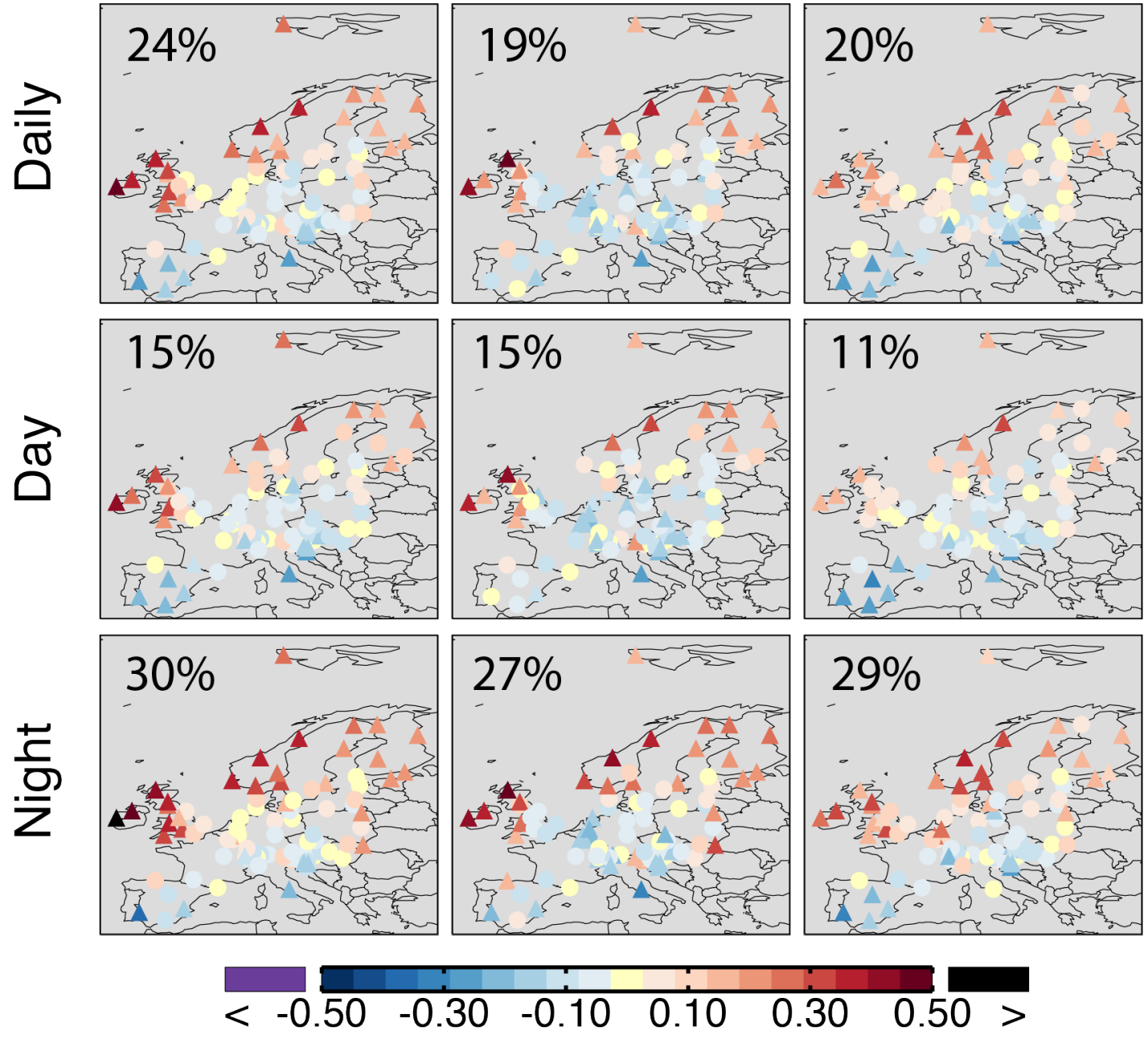

Fig. S10. Site-by-site correlations (triangle: P-value $<0.05$ under a $T$-test; circular: P-value $>$ 0.05 ) between NAO index and monthly mean, $5^{\text {th }}$ and $95^{\text {th }}$ percentile ozone in the daily data, and during daytime as well as nighttime. Also shown in each panel are the fraction of sites for which significant correlation exists. 


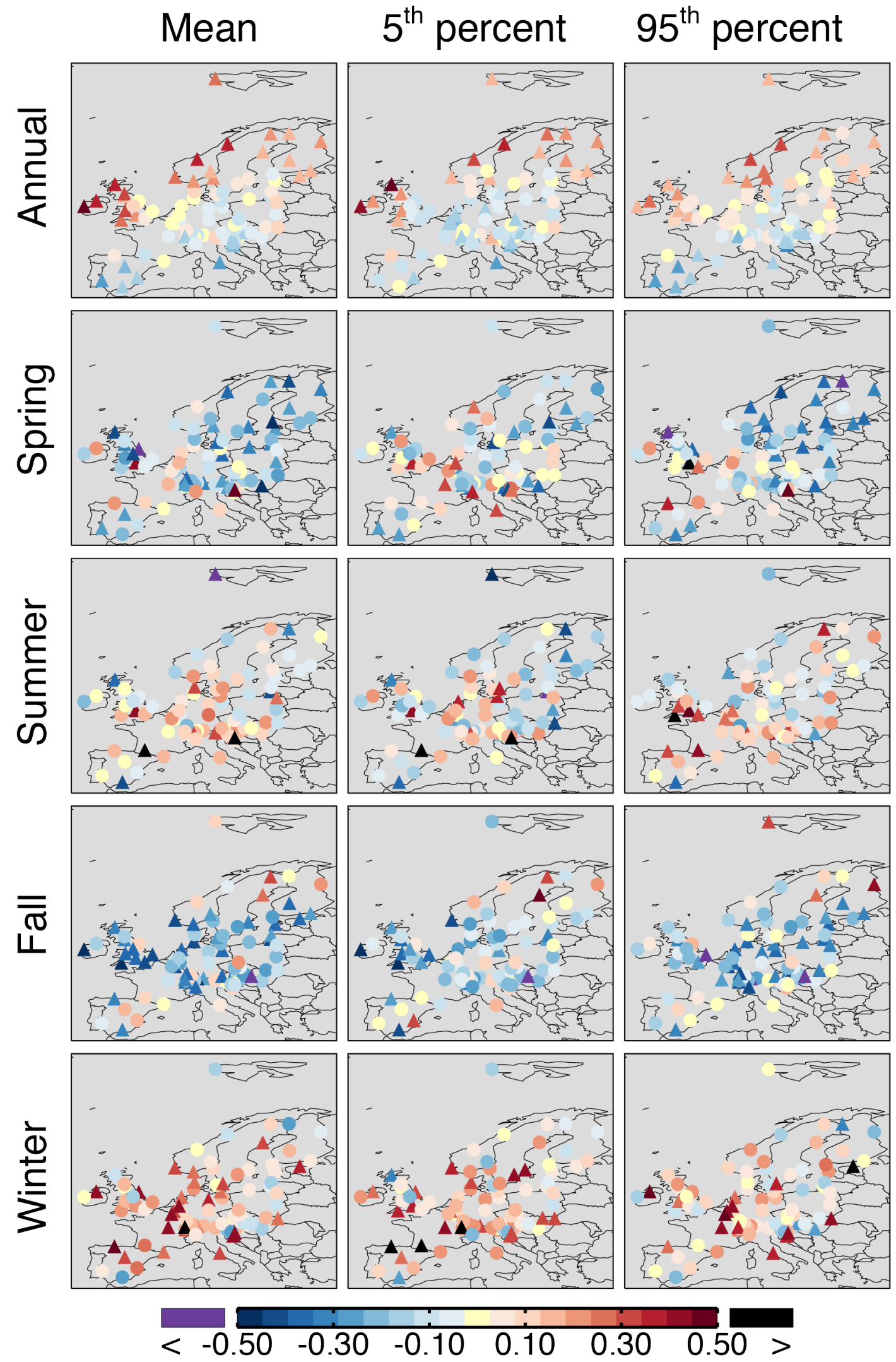

Fig. S11. Similar to Fig. S9, but for correlations between NAO index and ozone concentrations. 